\title{
Effects of Fiber-reinforced Composite Bases on Microleakage of Compos- ite Restorations in Proximal Locations
}

\author{
A. Tezvergil-Mutluay ${ }^{1, *}$ and P.K. Vallittu ${ }^{2}$
}

${ }^{I}$ Department of Restorative Dentistry and Cariology, Adhesive Dentistry Research Group, Institute of Dentistry, University of Turku, TYKS, Turku University Hospital, Turku, Finland

${ }^{2}$ Department of Biomaterials Science, and Turku Clinical Biomaterials Centre - TCBC Institute of Dentistry, University of Turku, Turku, Finland

\begin{abstract}
Objectives: The aim of this study was to evaluate the microleakage of direct restorative composite resin upon the addition of an intermediate glass fiber-reinforced composite (GFRC) layer of various fiber orientations between tooth and particulate filler composite resin (PFRC).

Materials and Methods: Cavities were prepared both on the mesial and distal surfaces of sixty extracted human molars with one margin placed below and the other above the cementoenamel junction (CEJ). Teeth were assigned to five different groups. Four of the groups received a layer of semi-interpenetrating polymer network (semi-IPN) resin system impregnated E-glass GFRC at the bottom of the cavity: Group 1; unidirectional continuous GFRC (EVS) in buccolingual direction (EVS-BL), Group 2; EVS in mesiodistal direction (EVS-MD), Group 3; bidirectional woven GFRC (EVN), Group 4; multidirectional short GFRC (EXP-MLT), Group 5; PRFC only (control). After acid etching and priming of the cavities and insertion of GFRC layer with the adhesive resin (Scotchbond Multipurpose 3M-ESPE), the cavities were filled incrementally with PRFC (Filtek Z250, 3M-ESPE) and each layer was light cured for $20 \mathrm{~s}$. After finishing and polishing, the restored teeth were water-stored for $24 \mathrm{~h}$ at $37{ }^{\circ} \mathrm{C}$ and then thermocycled for 6000 cycles between $5-55^{\circ} \mathrm{C}$, before immersion in $0.5 \%$ basic fuchsin dye for $24 \mathrm{~h}$. After sectioning by 3-5 sagittal cuts, each sequential section was imaged and digitally analyzed to determine the stain depth.
\end{abstract}

Results: All GFRC groups in dentin revealed significantly lower microleakage compared to control ( $\mathrm{p}<0.05)$. The orientation of FRC intermediate layer did not reveal significant differences in microleakage $(\mathrm{p}>0.05)$. The microleakeage in enamel was not different between the groups ( $p>0.05)$.

Conclusion: Use of intermediate GFRC layer between tooth and PFRC could provide alternative method to minimize microleakage.

Clinical Relevance: Use of GFRC intermediate layer underneath the particulate filler composite can be used to minimize the leakeage of the restorations.

Keywords: Fiber-reinforced composite, fiber direction, microleakage, resin composite

\section{INTRODUCTION}

In the last decade, the continuous improvement in adhesive systems and increased awareness among clinicians to protect and reinforce the remaining sound tooth structure, resulted in the increased use of particulate filler composite resin materials (PRFC) both at the anterior and posterior regions [1]. Despite the continuous improvement through modifications in formulation, polymerization shrinkage $[2$, 3] seems to be a problem for the PRFC. The polymerization reaction of the matrix of PRFC directly affects the dimensional stability of the composites. The polymerization of the

*Address correspondence to this author at the Department of Restorative Dentistry and Cariology, Institute of Dentistry, University of Turku, Lemminkäisenkatu 2, FIN-20520 Turku, Finland; Tel: +358 233383 75;

Fax: +358 233383 90; E-mail: arzu.tezvergil@utu.fi composites is mostly based on free radical polymerization of bifunctional dimethacrylate monomers that results in shrinkage of the composite [3-5]. During the shrinkage of the composite, the stresses are distributed to the adhesive layer and bonded tooth structure. If these stresses exceeds the bond resistance of the interface, they can result in damage to the tooth tissue or to the interface, or to the restoration itself, thereby leading to early failures of the system [5].

Microleakage is known as the passage of oral fluids, bacteria, molecules or ions between a restorative material and the cavity wall of the tooth $[6,7]$, is a common problem associated with polymerization contraction stress $[8,9]$, especially when the gingival margins extend below the cementoenamel junction (CEJ). The microleakage at the interface may lead to marginal staining, pulpal injuries and possibly recurrent caries [6-9]. 
Several factors are known to be important on the development of shrinkage in dental composites, including the matrix compositions of the composite, filler contents of the matrix, degree of conversion and light polymerization methods $[10,14]$. To reduce the stresses developed within the tooth restoration system, the use of various light polymerization methods [15], incremental filling methods [16], or ceramic inserts [17] have been proposed. However, these techniques are not yet considered sufficiently effective in large restorations in consideration of the polymerisation shrinkage of the current materials [18].

During the last decade, resin preimpregnated fibre reinforced composites have been introduced for dental use [19, 20]. Preimpregnation of the reinforcing fibers with the resin system by the manufacturers has proven to be important to produce high quality dental FRC restorations. The preimpregnation is based on using photopolymerizable dimethacrylate monomers or using a combination of dimethacrylate monomer resin and linear polymer which forms a semi-interpenetrating polymer network (semi-IPN) after polymerization. The semi-IPN matrices are highly viscous compared to the dimethacrylate system, which improves the handling properties as well as the bonding properties of the FRC after it has been polymerized [21, 22]. The easy handling of preimpregrnated systems extended the use of GFRC material in direct chairside applications [23, 24] for extensive restorations.

In contrast to PRFCs, the properties of GFRC are related to the fiber direction. Previously, the fiber orientation was shown to have a pronounced effect on the mechanical properties [20, 25], bonding properties [26] and thermal expansion [27] and polymerization shrinkage [28] of the GFRC. However, limited information exists about the effect of GFRC on the microleakage, although orientation of fibers could have an influence on this [29, 30].

Wide range of adhesive systems are available in the market, ranging from multi-step etch and rinse systems, which requires the separate application of etching, primer and adhesive, to one bottle self-etch non-rinse systems combining the etching, primer and adhesive into one bottle, containing the acidic monomers and solvents in the same bottle [31]. Despite general trend to simplify the adhesive steps etch and rinse adhesives are still proven to be the golden standard [31, 32] and have been shown to be compatible with the direct chair-side application of the GFRC [33, 34].

Therefore, this in vitro study aimed to investigate the effect of adding an intermediate semi-interpenetrating polymer network resin system GFRC with different fiber orientations on microleakage of composite resin restoration after thermocycling.

\section{MATERIALS AND METHODS}

Sixty extracted sound human third molars free of visible caries and cracks were selected for this study. The teeth were obtained from 18- to 25-year-old patients with an informed consent under a protocol approved by the Turku University Hospital District and used within one month of extraction. Upon collection, the soft tissues were carefully cleaned and the teeth were stored in $0.5 \%$ chloramin- $\mathrm{T}$ solution at $4{ }^{\circ} \mathrm{C}$ until further use. Before preparation, the teeth were mounted in a cylindrical block (diameter $2.5 \mathrm{~cm}$ ), $2 \mathrm{~mm}$ below the CEJ, using self-cure acrylic resin (Palapress, Heraeus Kulzer, Germany).

The maximum bucco-palatal and mesio-distal width of teeth were measured with a digital micrometer gauge (Mitutoyo, Kawasaki, Japan) with a tolerance of $10 \mu \mathrm{m}$ and teeth were included when variance of the mean was less than $5 \%$. Class II box cavities were prepared on the mesial and distal surfaces of each tooth. The cervical margin of one cavity located below $1 \mathrm{~mm}$ the CEJ, while the other one was located above the CEJ. The bucco-lingual width of each cavity was $5 \pm 0.5 \mathrm{~mm}$ on the occlusal and gingival side and the depth was $4.0 \pm 0.5 \mathrm{~mm}$ to the axial wall. The preparations were accomplished with diamond burs under water cooling and after that they were randomly assigned to one of the five experimental groups, corresponding to four GFRC materials, and the control group (PFRC) $(n=12)$. The primer, adhesive resin, PFRC and GFRC used in this study are listed in Table 1. Following cavity preparation the tooth surface were treated with $35 \%$ phosphoric acid (Ultraetch, Ultradent, South Jordan, UT, USA) for $15 \mathrm{~s}$, rinsed and gently air dried to maintain the visibly hydrated dentin surfaces. Primer (Scotchbond Multipurpose, 3M-ESPE) was applied and gently air dried for $5 \mathrm{~s}$ according to the manufacturer's recommendation. The adhesive resin was applied together with a layer of semi-interpenetrating polymer (semi-IPN) matrix GFRC having unidirectional, bidirectional or multidirectional orientation, and pressed to the etched and primed cavity using a silicon instrument recommended by the manufacturer (Refix D, StickTech, Turku, Finland). The GFRC layer was light-polymerized for $10 \mathrm{~s}$ with a hand-held light-curing unit (Elipar, ESPE, Seefeld, Germany) at a light intensity of $800 \mathrm{~mW} \mathrm{~cm}^{-2}$. The fibres were cut according to the cavity size using scissors and located $1 \mathrm{~mm}$ short of the margin (Fig. 1). In particular, Group 1 received unidirectional continuous GFRC (EVS) in buccolingual direction (EVS-BL), Group 2; EVS in mesiodistal direction (EVS-MD), Group 3; bidirectional GFRC (EVN), Group 4; multidirectional experimental GFRC (EXP-MLT), Group 5; PFRC only (Control) (Fig. 1). After the insertion of GFRC layer, the cavities were filled incrementally with PFRC of $1 \mathrm{~mm}$ increments and each layer was light cured for $20 \mathrm{~s}$.

The restorations were finished and polished using polishing discs in the recommended order (Sof-Lex, 3M ESPE). After finishing and polishing, restored teeth were stored in Grade 3 water at $37^{\circ} \mathrm{C}$ for $24 \mathrm{~h}$ and then thermocycled in water for $\left(6000\right.$ cycles, $5^{\circ} \mathrm{C}$ and $\left.55^{\circ} \mathrm{C}\right)$. The dwell time in each bath was $30 \mathrm{~s}$ and the transfer time between the baths was $5 \mathrm{~s}$. Twenty-four hours after thermocycling, all tooth surfaces were coated with a nail varnish, except a $1 \mathrm{~mm}$ wide zone around the margins of the restoration. After sealing, the teeth were immersed in $0.5 \%$ basic fuchsin dye for $24 \mathrm{~h}$ at $37{ }^{\circ} \mathrm{C}$. After basic fuchsin treatment, each tooth was cleaned in water and sectioned by 3-5 sagittal cuts using a low speed diamond saw (Isomet 1000 TM, Buehler, IL, USA) under water cooling. Each tooth-restoration section was examined under a stereo-microscope (Stereomicroscope, Wild M3B, Heerbrugg, Switzerland) at x40 magnification and the stain depth $(\mu \mathrm{m})$ along the buccal and lingual restoration interfaces was digitally analyzed (Leica DC Twain, 
Table 1. The materials used for this study.

\begin{tabular}{|c|c|c|c|c|c|}
\hline Materials & Code & Manufacturer & Lot & Composition & Material type \\
\hline $\begin{array}{c}\text { ScotchBond } \\
\text { Multi-purpose Adhesive } \\
\text { and primer }\end{array}$ & SB & 3M,St. Paul, MN, USA & $\begin{array}{c}\text { Adhesive } 20000907 \\
\text { Primer: } 20001120\end{array}$ & $\begin{array}{c}\text { Adhesive: HEMA, bisG- } \\
\text { MA } \\
\text { Primer: HEMA, water, } \\
\text { vitrebond copolymer }\end{array}$ & Bonding agent \\
\hline EverStick $^{*}$ & EVS & $\begin{array}{l}\text { StickTech Ltd., Turku, Fin- } \\
\text { land }\end{array}$ & 2010723-ES & E-glass, PMMA, bisGMA & $\begin{array}{l}\text { Resin preimpregnated continu- } \\
\text { ous unidirectional GFRC }\end{array}$ \\
\hline EverStickNet $^{*}$ & EVN & StickTech, Turku, Finland & 2040122-EN-061 & $\begin{array}{l}\text { PMMA, bisGMA, E-glass } \\
\text { fibres }\end{array}$ & $\begin{array}{l}\text { Resin preimpregnated continu- } \\
\text { ous bidirectionally oriented } \\
\text { GFRC }\end{array}$ \\
\hline $\begin{array}{c}\text { Experimental } \\
\text { multidirectional GFRC }\end{array}$ & EXP-MLT & StickTech, Turku, Finland & NA & $\begin{array}{l}\text { bisGMA,E-glass fibers, } \\
\text { PMMA, }\end{array}$ & $\begin{array}{c}\text { Resin preimpregnated randomly } \\
\text { oriented GFRC }\end{array}$ \\
\hline Filtek Z250* & GPFC & 3M, St.Paul, MN, USA & 20000523 & $\begin{array}{c}60 \% \text { vol fillers bisG- } \\
\text { MA,UDMA } \\
\text { bis-EMA }\end{array}$ & $\begin{array}{l}\text { Hybrid type particulate filler } \\
\text { composite resin }\end{array}$ \\
\hline
\end{tabular}
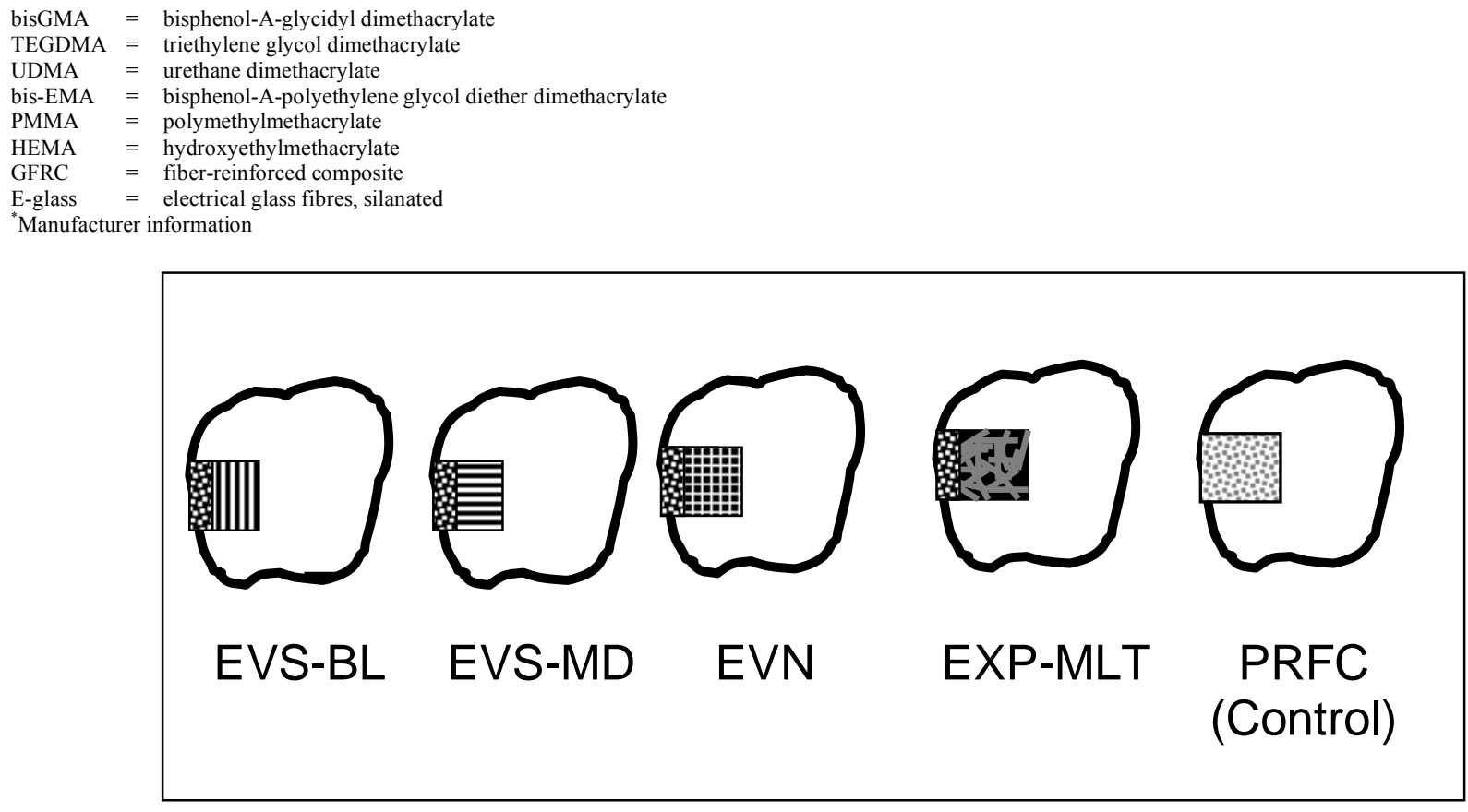

Fig. (1). Schematic figure representing test groups. EVS-BL; unidirectional continuous GFRC located in buccolingual direction, EVS-MD unidirectional continuous GFRC located in mesiodistal direction, EVN, bidirectional continuous GFRC, EXP-MLT multidirectional experimental GFRC, PFRC (Particulate filler composite).

Leica Microsystem Imaging Solutions Ltd). The microleakage value for each section was obtained by calculating the mean dye penetration along the buccal and lingual restoration margins (Fig. 1). Finally, the microleakage of each tooth specimen was recorded by calculating the mean microleakage values of the 3-5 sections.

The data for all the groups were analysed statistically with SPSS 19.0 (Statistical Package for Statistical Science, SPSS Inc., Chicago, Illinois, USA). All groups were compared for normality (Kolmogorov-Smirnov test) and homoscedasticity (modified Levine test). As the normality and equality variance assumptions of the data were violated, sta- tistical comparisons of the groups were made using KruskalWallis and Conover's multiple comparison tests. The level of significance was set at $p=0.05$.

\section{RESULTS}

The means and standard deviations of stain penetration depths $(\mu \mathrm{m})$ in enamel and dentin are presented in Fig. (2). Both the existence of GFRC intermediate layer and the location of the cavity had a significant effect on microleakage $(p<0.05)$. The interactions between the factors were also significant $(\mathrm{p}<0.05)$. The mean dye penetration along the dentin 


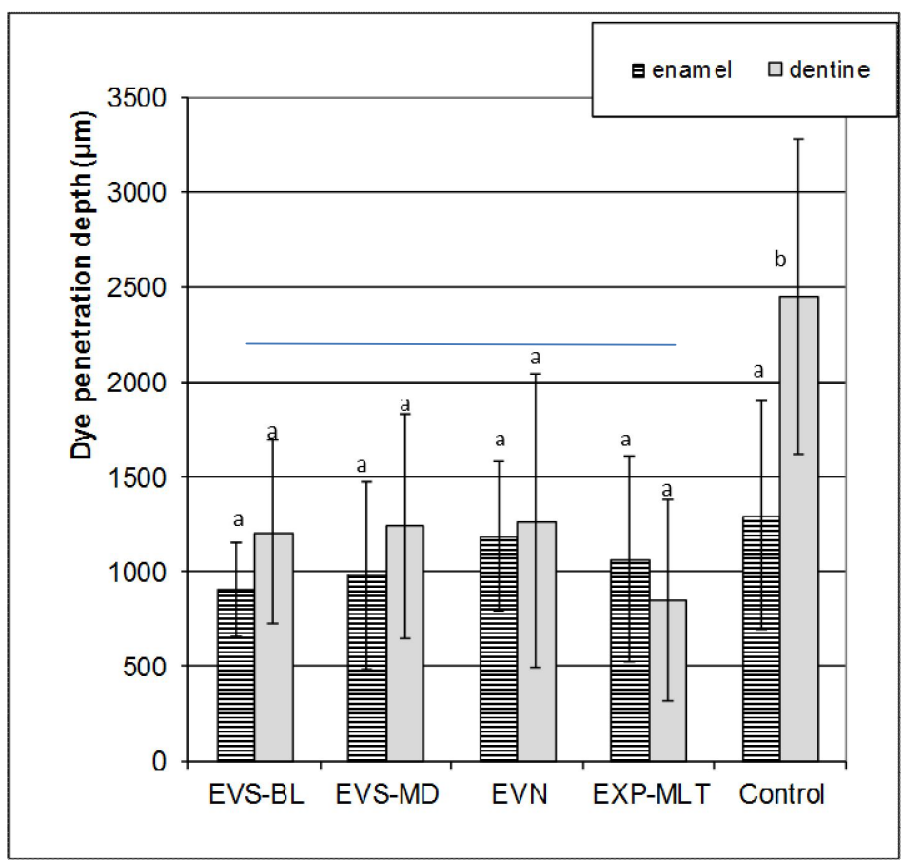

Fig. (2). Mean stain depth $(\mu \mathrm{m})$ and standard deviations in enamel and dentin. Vertical lines represent standard deviations. For abbreviations, see Fig. (1).

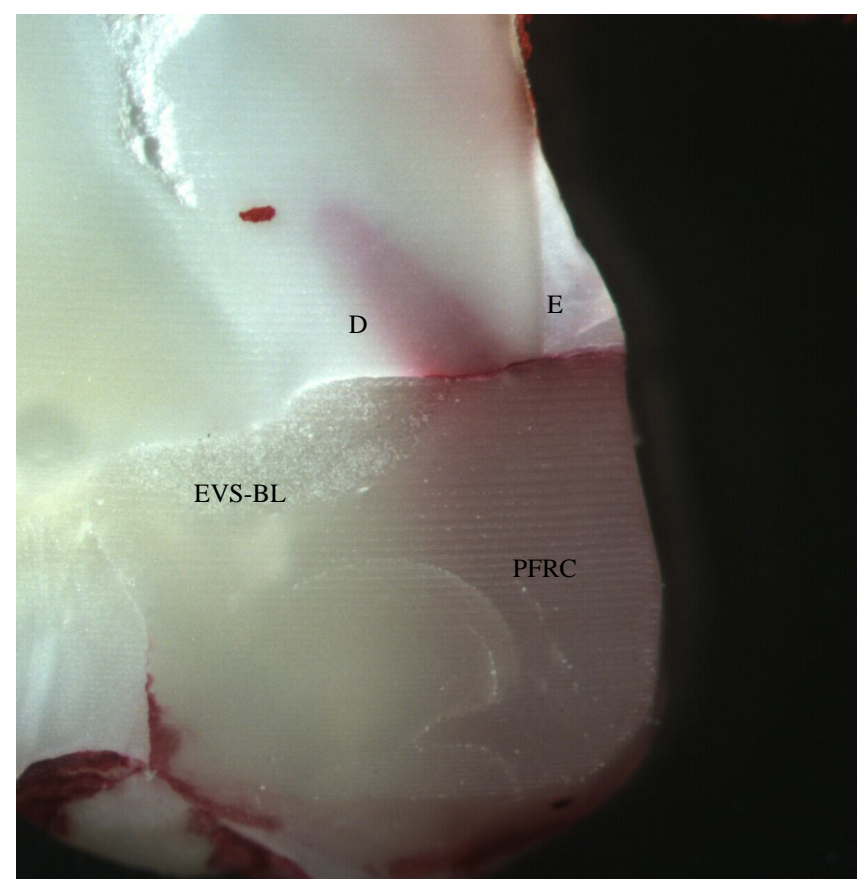

Fig. (3). The representative tooth sections with unidirectional EVS-BL GFRC at the interface. D: corresponds for dentin. E: refers to enamel For abbreviations refer to Fig. (1).

margins was significantly higher than that of the enamel margins in control group ( $\mathrm{p}<0.05)$, but not in GFRC groups $(p>0.05)$. The intermediate GFRC layer showed significant effect in microleakage in dentin compared to control $(p<0.05)$. The orientation of GFRC intermediate layer did not reveal any significant differences in microleakage (p>0.05). Figs. (3 and 4) show the representative tooth sections with and without GFRC at the interface.

\section{DISCUSSION}

This study was designed to evaluate the effect of a semiinterpenerating polymer network matrix GFRC with different fibre orientations on the microleakage of Class 2 cavities. The rationale for comparing the simulated direct application of a GFRC intermediate layer with PFRC in Class 2 cavities came from their potential to be used in extensive adhesive 


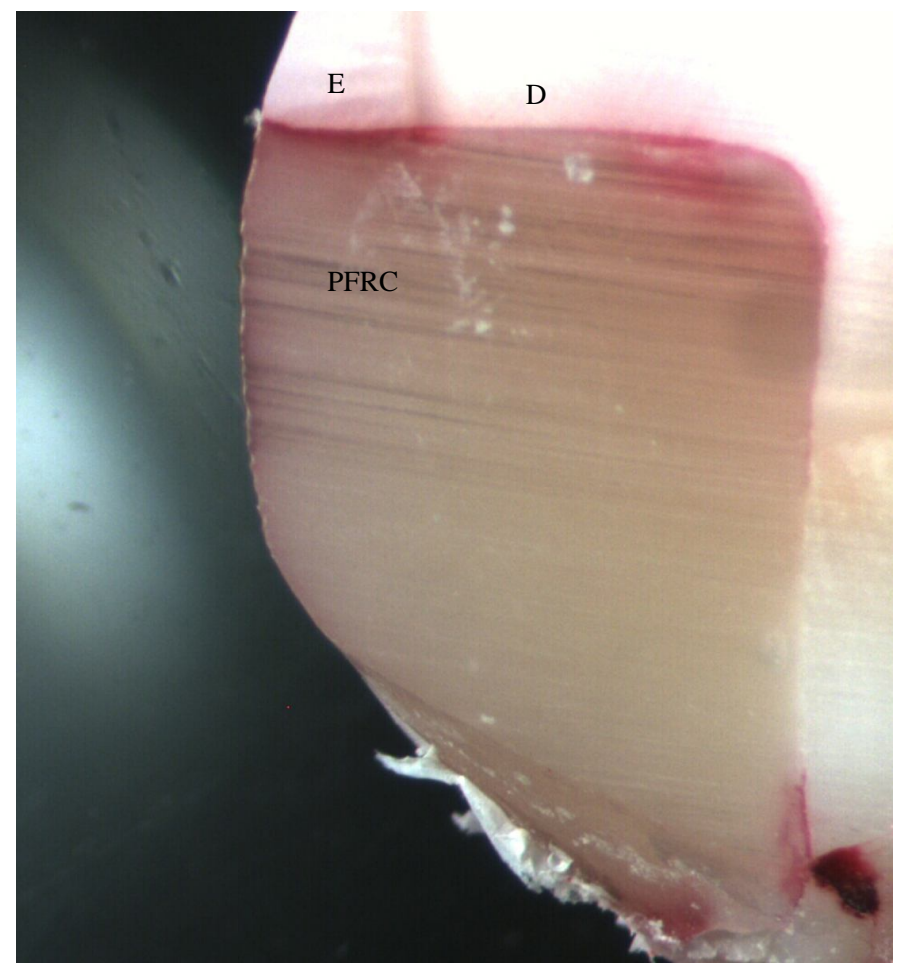

Fig. (4). The representative tooth sections without GFRC at the interface. D: corresponds for dentin. E: refers to enamel. For abbreviations refer to Fig. (1).

restorations to increase the load bearing capacity and change the failure mode of the resultant restoration [25, 29, 30]. Moreover, bidirectional and multidirectional GFRCs were evaluated as it could be that the properties of these can possibly mimic the biomechanics of tooth structure better than unidirectional GFRCs and the handling in cavities might be better than the unidirectional ones.

A good marginal seal is an important issue for the long term success of a restoration. Durable bonding properties to enamel and dentin would be one of the key issues to reduce marginal microleakage. Many studies have shown that bonding between the resin materials and enamel is adequate to resist contractions stresses $[32,33]$. This was also confirmed in the current study, as the microleakage measured at the enamel margin for all the tested materials was lower than the dentin margins. This might be the result of the highly effective enamel bond of the total etching adhesive system even after thermocycling [32, 33]. The cervical enameldentin/resin composite interface has been reported to be more vulnerable to microleakage. The results of the currents study is in line with the previous studies, showing significantly higher microleakage at the dentin margins.

The adhesive system that contained hydroxyethylmethacrylate (HEMA) was selected for this study. Low molecular weight HEMA could effectively penetrate to the linear phases of the semi-IPN matrix GFRC even after polymerization of the matrix resulting in better bonding properties [26, 33, 34]. Since the bonding agent used in the current study does not contain ethanol or acetone, the possible residual solvent action of the adhesive system on the GFRC material could be avoided [26, 34].
The use of a low elastic modulus layer was suggested to act as a stress breaker and placement of a thin layer of a low viscosity, low elastic modulus resin, between the adhesive layer and the composite, was suggested to compensate for the negative effects of the polymerization shrinkage [35]. Fiber reinforced composites have elastic modulus very close to dentin, which might act as a stress breaker between the composite resin and dentin, therefore no additional low viscosity composite was used in this study [26, 27].

Low polymerization shrinkage is important to achieve good dimensional stability, which in turn could directly affect the microleakage, and improve the marginal integrity and longevity of the restoration $[8,9]$. Previously, polymerization shrinkage of GFRC was shown to be affected by the orientation of the fibers in the matrix [28]. Compared to isotropic PFRC having $60 \%$ fillers, an anisotropic GFRC, having similar volume percent of fibers as fillers showed $75 \%$ less shrinkage in transversal direction and negligible shrinkage strain in the longitudinal direction along the fibres [28]. On the other hand, the shrinkage strain of bidirectional and multidirectional GFRC was 15-20 times less compared to isotropic PFRC, which was attributed to the constraints applied by the fibres in both directions [28]. Previously bond strength of unidirectional GFRC has been reported to be higher in enamel [33], whereas bond strength of bidirectional GFRC was higher in dentin [26]. Therefore, authors hypothesized that there could be a significant difference in microleakage according to the orientations of fibers of at the GFRC intermediate layer. Within the limitations of this study, this hypothesis was rejected. Despite the significantly low shrinkage in dentin compared to the control PFRC material, there were no differences in microleakage among differ- 
ent fibre orientations. Furthermore, even though multidirectional GFRC showed a mean stain penetration depth to be lower than the others in dentin, this difference was not statistically significant.

The linear coefficient of thermal expansion of a material is an important contributing factor to microleakage [6]. Despite the reported differences in thermal expansion of GFRC in different directions (Linear coefficient of thermal expansion $\left(10^{-6} / \mathrm{C}^{\circ}\right)$ at transversal direction being 52.3 versus along the fibers being 9.1) [27], after thermocycling, there was not any significant difference in microleakage among GFRC with different orientations. This might be due to the fact that, the fibres were not exposed directly to the oral cavity. Due to the slow rate of thermal diffusion through polymer matrix and overlaying PFRC resin, the GFRC was perhaps not greatly affected by thermal change of the thermocycling.

Within the limitations of the current study, it can be concluded that the addition of an intermediate GFRC layer showed significantly lower microleakage in dentin compared to PFRC only but the influence of orientation of fibers at the intermediate layer was not able to be demonstrated. Current study did not look into the factor of loading or the biofilm formation which may affect the bonding and hence leakage of the restoration. These parameters will be evaluated at future studies. Therefore the results should be interpreted with care when it is applied to clinical condition.

\section{CONFLICT OF INTEREST}

The author AT-M declare no conflict of interest. Author PV consults Stich Tech-GC in RD and training.

\section{ACKNOWLEDGEMENTS}

This study was carried out at the former Biomechanical Testing Laboratory (currently Turku Clinical Biomaterials Centre - TCBC) of the Institute of Dentistry at the University of Turku. The kind help of laboratory personnel is greatly appreciated. The study was supported by grant \#8126372 from the Academy of Finland (P.I. AT-M). The investigated materials were provided in part by the manufacturers. This is greatly appreciated.

\section{REFERENCES}

[1] Ilie N, Hickel R. Resin composite restorative materials. Aust Dent J 2011; 56: 59-66.

[2] Mantri SP, Mantri SS. Management of shrinkage stresses in direct restorative light-cured composites: a review. J Esthet Restor Dent 2013; 25: 305-13.

[3] Frankenberger R, Garcia-Godoy F, Murray PE, Feilzer AJ, Krämer $\mathrm{N}$. Risk aspects of dental restoratives: from amalgam to toothcolored materials. World J Stomatol 2013; 2: 1-11.

[4] Watts DC, Marouf AS, Al Hindi AM. Photo-polymerization shrinkage-stress kinetics in resin composites at standardized compliance: methods development. Dent Mater 2003; 19: 1-11.

[5] Schoch KF, Panackal PA, Frank PP. Real-time measurement of resin shrinkage during cure. Thermochimica Acta 2004; 417: 1158.

[6] Kidd EA. Microleakage: A review. J Dent 1976; 4: 199-206.

[7] Alani AH, Toh CG. Detection of microleakage around dental restorations: A review. Oper Dent 1997; 22: 173-85.
[8] Calheiros FC, Sadek FT, Braga RR, Cardoso PE. Polymerization contraction stress of low-shrinkage composites and its correlation with microleakage in Class V restorations. J Dent 2004; 32: 40712.

[9] Sultan A, Moorthy A, Fleming GJ. The adhesive potential of dentin bonding systems assessed using cuspal deflection measurements and cervical microleakage scores. Dent Mater 2014; pii: S01095641(14)00189-4. doi: 10.1016.

[10] Goncalves F, Pfeifer CS, Ferracane JL, Braga RR. Contraction stress determinants in dimethacrylate composites. J Dent Res 2008; 87: 367-71.

[11] Atai M, Watts DC. A new kinetic model for the polymerization shrinkage-strain of dental composites and resin monomers. Dent Mater 2006; 22: 785-91.

[12] Shah PK, Stansbury JW. Role of filler and functional group conversion in the evolution of properties in polymeric dental restoraties. Dent Mater 2014; 30: 586-93.

[13] Irie M, Tanaka j, Maruo Y, Nishigawa G. Vertical and horizontal polytmerization shrinkage in composite restorations. Dent Mater 2014; 30: 189-98.

[14] Watts DC. Reaction kinetics and mechanics in photo-polymerised networks. Dent Mater 2005; 21: 27-35.

[15] Fleming GJ, Cara RR, Palin WM, Burke FJ. Cuspal movement an microleakeage in premolar teeth restored with resin-based filling materials using a 'soft start'polymerization protocol. Dental Mater 2007; 23: 637-43.

[16] Lutz F, Krejci I, Oldenburg TR. Elimination of polymerization stresses at the margin of posterior composite resin restorations: a new restorative technique. Quint Inter 1986:17: 777-84.

[17] Donly KJ, Wild TW, Bowen RL, Jensen ME. An in vitro investigation of the effect of glass inserts on the effective composite resin polymerization shrinkage. J Dent Res 1989; 68: 1234-7.

[18] De Gee AJ, Feilzer A, Davidson CL. True linear polymerization shrinkage of unfilled resins and composites determined with a linometer. Dent Mater 1993; 9: 11-8.

[19] Freilich MA, Karmaker AC, Burstone CJ, Goldberg AJ. Development and clinical applications of a light-polymerized fiberreinforced composite. J Prosthet Dent 1998; 80: 311-8.

[20] Vallittu PK. Flexural properties of acrylic resin polymers reinforced with unidirectional and woven glass fibers. J Prosthet Dent 1999; 81: 318-26.

[21] Lastumäki TM, Lassila LVJ, Vallittu PK. The semiinterpenetrating polymer network matrix of fiber-reinforced composite and its effect on the surface adhesive properties. J Mater Sci Mater Med 2003; 14(9): 803-9.

[22] Lastumaki TM, Kallio TT, Vallittu PK. The bond strength of lightcuring composite resin to finally polymerized and aged glass fiberreinforced composite substrate. Biomater 2002; 23: 4533-9.

[23] Vallittu PK, Sevelius C. Resin-bonded, glass fiber-reinforced composite fixed partial dentures: a clinical study. J Prosth Dent 2000; 84: 413-8.

[24] Meiers JC, Freilich MA. Conservative anterior tooth replacement using fiber-reinforced composite. Oper Dent 2000; 25: 239-43.

[25] Fennis WM, Tezvergil A, Kuijs RH, Lassila LV, Kreulen CM, Creugers NH, Vallittu PK. In vitro fracture resistance of fiber reinforced cusp-replacing composite restorations. Dent Mater 2005; 21: 565-72.

[26] Tezvergil A, Lassila LV, Vallittu PK. The shear bond strength of bidirectional and random-oriented fibre-reinforced composite to tooth structure. J Dent 2005; 33: 509-16.

[27] Tezvergil A, Lassila LV, Vallittu PK. The effect of fiber orientation on the thermal expansion coefficients of fiber-reinforced composites. Dent Mater 2003; 19(6): 471-7.

[28] Tezvergil A, Lassila LV, Vallittu PK. The effect of fiber orientation on the polymerization shrinkage strain of fiber-reinforced composites. Dent Mater 2003; 22: 610-6.

[29] Belli S, Orucoglu H, Yildirim C, Eskitascioglu G. The effect of fiber placement or flowable resin lining on microleakage in Class II adhesive restorations. J Adhes Dent 2007; 9: 175-81.

[30] Belli S, Erdemir A, Ozcopur M, Eskitascioglu G. The effect of fibre insertion on the fracture resistance of root filled molar teeth with MOD preperations restored with composite. Int Endo J 2005; 38: 73-80.

[31] Pashley DH, Tay FR, Breschi L, et al. State of the art etch-andrinse adhesives. Dent Mater 2011; 27: 1-16. 
[32] Fradeani M, Redemagni M, Corrado M (2005). Porcelain laminate veneers: 6- to 12 year clinical evaluation-a retrospective study. Int J Periodont Restor Dent 2005; 25: 9-17.

[33] Tezvergil A, Lassila LV, Vallittu PK. Strength of adhesive-bonded fiber-reinforced composites to enamel and dentin substrates. J Adhes Dent 2003; 5: 301-11.

[34] Tezvergil-Mutluay A, Lassila LV, Vallittu PK. The microtensile bond strength of semi-interpenetrating polymer matrix fiber- reinforced composite to dentin using various bonding systems. Dent Mater J 2008; 27: 821-6.

[35] Lo Giudice G, Cicciù M, Cervino G, Lizio A, Visco AM. Flowable resin and marginal gap on tooth third medial cavity involving enamel and radicular cementum: A SEM evaluation of two restoration techniques . Ind J Dent Res 2012; 23: 763-9.

Received: July 21, 2014

Revised: September 10, 2014

Accepted: September 28, 2014

(C) Tezvergil-Mutluay and Vallittu; Licensee Bentham Open.

This is an open access article licensed under the terms of the Creative Commons Attribution Non-Commercial License (http://creativecommons.org/licenses/by-nc/3.0/) which permits unrestricted, non-commercial use, distribution and reproduction in any medium, provided the work is properly cited. 